\title{
Quantum Information Science- The Domain of Future Informatics Practice: Emphasizing Possibilities, Challenges and Academic Scenario
}

\author{
P. K. Paul ${ }^{\text {* }}$, A. Bhuimali ${ }^{2}$, P. S. Aithal ${ }^{3}$, K. L. Dangwal ${ }^{4}$ \\ ${ }^{1}$ DCIS, Raiganj University (RGU), West Bengal, India \\ ${ }^{2}$ Vice Chancellor, Srinivas University, Karnataka, India \\ ${ }^{3}$ Vice Chancellor, Raiganj University (RGU), West Bengal, India \\ ${ }^{4}$ Department of Education, University of Lucknow, UP, India \\ *Corresponding Author: pkpaul.infotech@gmail.com
}

\begin{abstract}
Available online at: www.isroset.org
Receive $06^{\text {th }}$ Aug 2017, Revised $14^{\text {th }}$ Aug 2017, Accepted $18^{\text {th }}$ Sep 2017, Online $30^{\text {th }}$ Oct 2017

Abstract-'Quantum'- is one of the important and valuable names in the field of Physical Science. However, due to its importance and applications in several sectors or domains; it is treated as valuable Applied Science Field. Quantum in generally has important linkages with Physics and then Mathematics. The importance of Quantum in Computing developed a domain called Quantum Computing which is responsible for healthy and speedy Computing and Technological Science. Computing has an important relationship with Information Science. Information collection, selection, organization, processing and management and dissemination are the main roles of Information Science and for building and developing such information activities; computing tools play an important role. Thus, Quantum Computing is also helpful in better Information Science Practice and ultimately responsible for sophisticated Informatics practice. In this paper, Quantum Science and Information Science, and their integration role as Quantum Information Science; including its need, value and role are discussed and analyzed.
\end{abstract}

Keywords-Quantum Information Science, Quantum Computing, Quantum Technology, Informatics, Information Transfer Cycle, ITC, Quantum Effects.

\section{INTRODUCTION}

Information Science is one of the important interdisciplinary domains around the world; Information Science emerged during 1970-1980's; however, the concept or term emerged during 1960's when 'Information' term first used. Initially, Information Science was treated as important social science domain and mainly dedicated to information activities with manual tools and techniques such as cataloguing, classification, and indexing, abstracting, documentation and so on [01, 03]. But the advancement of IT and Computing and their integration of Information Science change the entire arena of Information Science and make that as an important domain of Applied Science responsible for smart and intelligent Information Practice. Thus, this interdisciplinary nature continuous and creates relationship with so many domains such as Management Science, Marketing, Cognitive Science, Information Studies, and so on. Like these clustering and integration of Quantum Science and more clearly Quantum Computing with Information Science results completely a new domain called Quantum Information Science. Today Quantum Information Science is an important knowledge gradient not only in Applied
Science but also in Technological World [04]. Refer Fig: 1, Fig: $2 \& 4$.

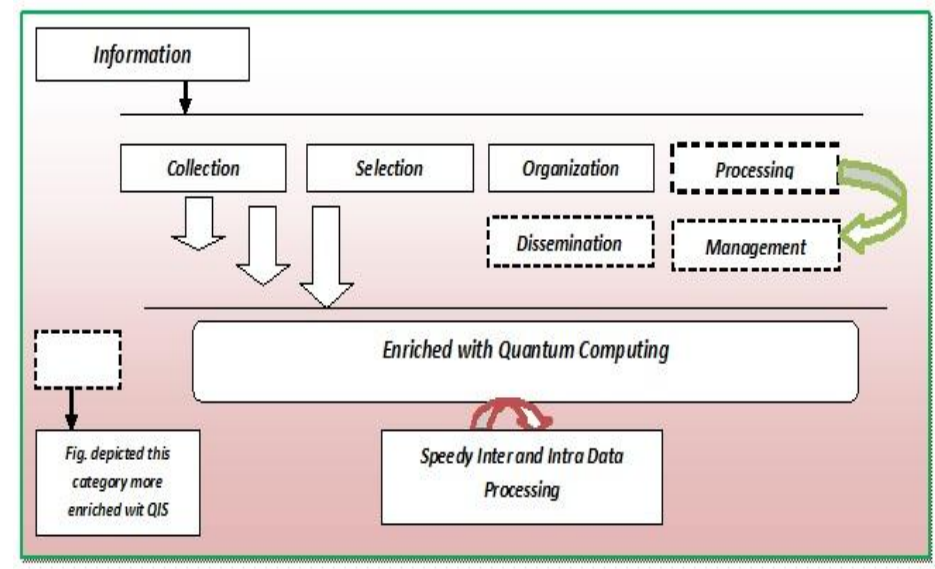

Fig: 1-Depicted basic role of QIS in Information Processing and other information activities 


\section{OBJECTIVE}

The main aim and objective of this conceptual study is includes but not limited to as follows

- $\quad$ To know basic about Quantum Science and its related domain and facets;

- To know about Quantum Information Science and its basic nature;

- To learn about Quantum Information Science and origin, briefly;

- To know more about Quantum Information Science and its value in contemporary Information world;

- To find out challenges and application of Quantum Information Science at a glance.

\section{INFORMATION SCIENCE PRACTICE AND QUANTUM INFORMATION SCIENCE: FUNDAMENTALS}

Before reaching on Quantum Information Science lets talk about Information Science. Information Science is most controversial and interdisciplinary domain with several domains based nature and tools based nature. Information Science in generally, an information field responsible for information processing and management; but individually it acts as a domain for information collection, selection, processing, management, and dissemination with several tools and technologies $[05,08]$. The advancement in computing in Information Science changes entire Information Activities. The technologies such as Database Technologies, Networking Technologies, Communication Technologies, and Multimedia Technologies are changes entire the traditional Information Science field.

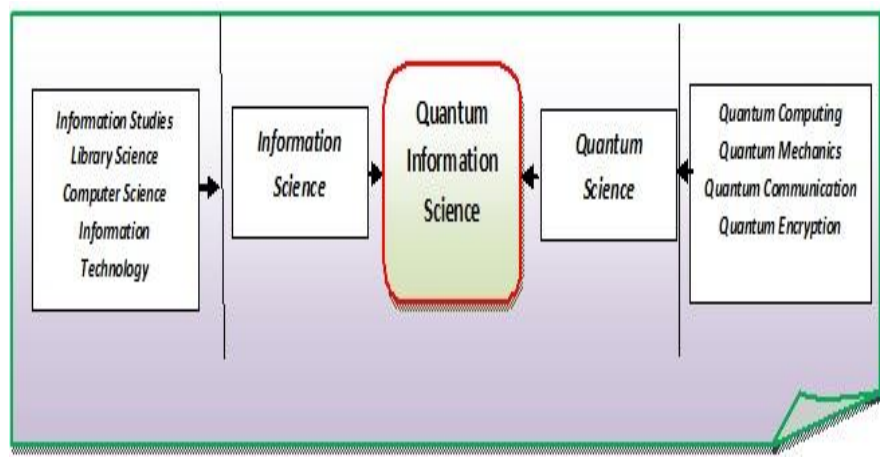

Fig: 2-Depicted Building of QIS as a field from merging of Information Science and Quantum Science

The interaction and application of Information Science in another field also results so many other domains such as
Geography and Information Science brings- Geo Information Science or Geo Informatics, Health Science and Information Science also brings- Health Information Science/ Health Informatics and like these so many other domains. Thus, Quantum Science and Information Science and their application and integration result in Quantum Information Science or QIS. Quantum Information Science is a new field which is responsible for faster and advance communication powered by Qbit. In today's and future supercomputers, Qbits may be used to solve hard problems and may be able in speed up communication in computation. In Quantum Information Science, quantum powered computer and other machines are able to improve the processor speed and here many processors are working parallel way. This is the result of the integration of computation, communication, processor measurement and fundamentals of Quantum Science [09].

\section{QUANTUM INFORMATION SCIENCE: ROLE AND IMPORTANCE}

Quantum Information Science brings so many opportunities in information processing and management and overall information infrastructure building. Some of them are :-

- Quantum Information Science is enriched with Quantum Networks and which is developed with Quantum Computing and QBit powered computers and thus helps in transparent Information and Communication between several components;

- Quantum Information Science results may vary at high speed and faster information transfer cycle and thus it promotes several information tasks likecollection, selection, organization, processing, and dissemination $[10,11]$;

- It helps to build smart and sophisticated Information Foundation such as Information Networks, Information Systems, Information Centre, Data Centre, Cloud Computing services and so on;

- A Quantum Information Science based computer is capable in efficient and accurate evaluation of quantum systems [12];

- Quantum Information Science is helpful to process billion of data within a small moment which is in normal computing take huge time;

- In Information Science traditional practices including General Information Foundation, it is 
possible to speed up many activities mainly in Knowledge Networks and Knowledge Grids;

- It promotes healthy and speedy internet and systems and helps in Big Data Management.

\section{QUANTUM INFORMATION SCIENCE: CHARACTERISTICS AND CHALLENGES}

During 1970's- 80's some Scientist integrated Quantum Mechanics with classical truing computing machine. During 1990 's and mid of 1990's IT industry realize the benefit of Quantum Computing and integrated Quantum powered processor and chips (depicted in Fig: 3). Some of the important features of Quantum Information Science are-

- Quantum Information Science is a new field in Science and Technology and integrated by so many fields such as Computer Science, Information Science, Mathematics, Physical Science, Engineering Science and so on;

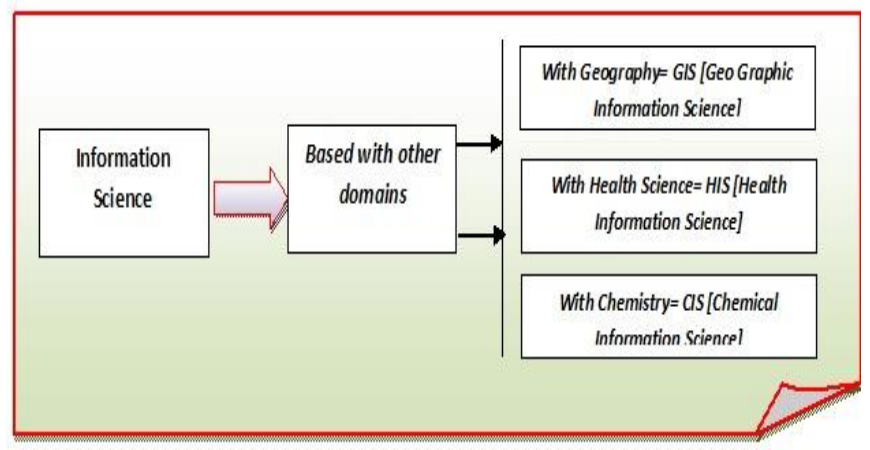

Fig: 3-Showing Information Science and domain based New subject creation by merging other domain

- $\quad$ The main field of Quantum Information Science is Quantum Science and which is based on Quantum Physics, Quantum Mechanics, Quantum Computing and so on;

- Information carried by Quantum Information Science is run by the Quantum Systems flouts such as common sense principles $[09,15]$;

- Quantum Information Science is large scale computing dependent and thus it process information very very speedy manner;

- As NSF-USA mentioned, Quantum Information Science is an intellectual exciting field with far reaching implications for the basic mathematical and physical science, theoretical and experimental;
- Information in Quantum Information Science is processed in a system which is a combination of Quantum enriched and powered computer, network devices and other hardware;

- In Quantum Information Science, Quantum Computing is used to make highly capable computer, channel, and processor with exceptional speed;

- Quantum Information Processing is mainly powered by scaling; so that optical fiber networks play a big role;

- Quantum Communication complexity is another most important domain for the Quantum Information Science.

Quantum Information Science is challenging too, as it needs several activities, gradients and other focus in a combined way. Quantum Searching and lower bounds are also important aspects to look into. However, one of the most important recent developments in this field and one most important thing is the discovery of unknown Quantum states if properly encoded protects from the error [04, 09, 12].

\section{QUANTUM INFORMATION SCIENCE: ACADEMICS AND APPLICATIONS}

As far as academics is concerned, Quantum Information Science still does not get proper recognition as an academic field. However, it is important to note that several academic initiatives are initiated around the world (listed in Table: 1).

\begin{tabular}{|c|c|}
\hline QIS and related programme & Universities and Institutes \\
\hline MSc in Quantum Technologies & $\begin{array}{c}\text { School of Physics and } \\
\text { Astronomy, University of Leeds, } \\
\text { UK }\end{array}$ \\
\hline MSc-Quantum Information & $\begin{array}{c}\text { Institute of Quantum Computing, } \\
\text { University of Waterloo, CA }\end{array}$ \\
\hline $\begin{array}{c}\text { Short term work shop, Training } \\
\text { etc. }\end{array}$ & $\begin{array}{c}\text { Centre for Quantum Information } \\
\text { and Quantum Computation, IISc, } \\
\text { Bangalore, India }\end{array}$ \\
\hline $\begin{array}{c}\text { MSc-Quantum Information and } \\
\text { Computing }\end{array}$ & $\begin{array}{c}\text { Department of Physics, } \\
\text { Loughborough University } \\
\text { Leicestershire, UK }\end{array}$ \\
\hline
\end{tabular}

Table: 1 Depicted general and popular courses related to Quantum Computing and Information

Today in some Western countries Quantum Information Science offered as full-fledged academic programme with Bachelor and Master Degree and in some Universities it has 
been offered as MSc-Chemistry [Quantum Information Science], MSc-Physics [Quantum Information Science], MSc-Mathematics [Quantum Information Science].

Still as far as the study is concerned not a single Information Schools/ I-Schools found with Quantum Information Science as a specialization in Information Science; however, so many other specializations are available such as

-Health Information Science;

-Geo Information Science;

-Chemo Information Science;

-Bio Information Science and so on $[17,18]$.

Quantum Information Science has potential to offer in so many academic domains in which this is related directly and indirectly like- IT, Computer Science, Physics, Mechanical Engineering and so on. However, in so many countries, Quantum Information Science is available as a paper or module in Bachelor or Masters Degree [09].

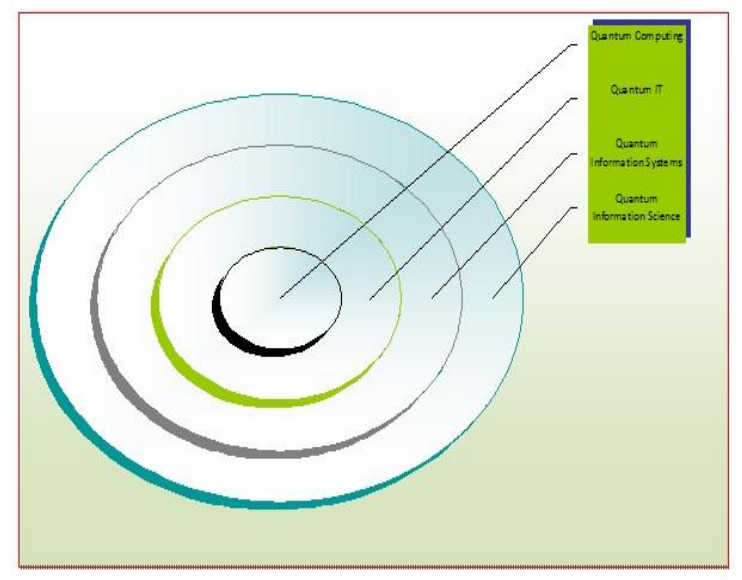

Fig: 4-Depicted QIS and its smaller knowledge gradients at a glance

Due to so many benefits, Quantum Information Science is applicable in so many domains and dimension in the fields such as Health, Business, and Education and so on. Healthy Quantum Information Science enriched Information Systems and may bring healthy information and communication, Tele Medicine, and Video Conferencing facilities in several health centres or places located various parts of the country or worldwide. Like this, in Business Informatics also, Quantum Information Science may be applied for healthy and quick Information Processing, generation, and reporting to decision making process. In Education field also, Quantum Information Science may bring healthy E-Learning, Online Education, and sophisticated campus based Educational Practice.

\section{FINDINGS}

- Quantum Information Science broadly combined with Information Science and Quantum Science;

- QBit is the main stakeholder in Quantum Information Science;

- Still, academic programme in Quantum Information Science and related domain is limited around the world; though it has wonderful potentials;

- The current research and development activities promote overall proper Information Infrastructure in near future.

\section{CONCLUSION}

Quantum Algorithm is the smallest facet and gradients in Quantum Information Science. However, after Quantum algorithms; Quantum Cryptography and Quantum Information Systems take place. Information is the power of society and development.

It is needed in almost all the sector, institution, domain and individual life [02, 04, 09, 16]. Without information, today we can't survive and the proper implementation of technologies such as Quantum Computing and broadly Quantum Information Systems helps in overall Information Processing and Management (A detail is provided in Fig: 5).

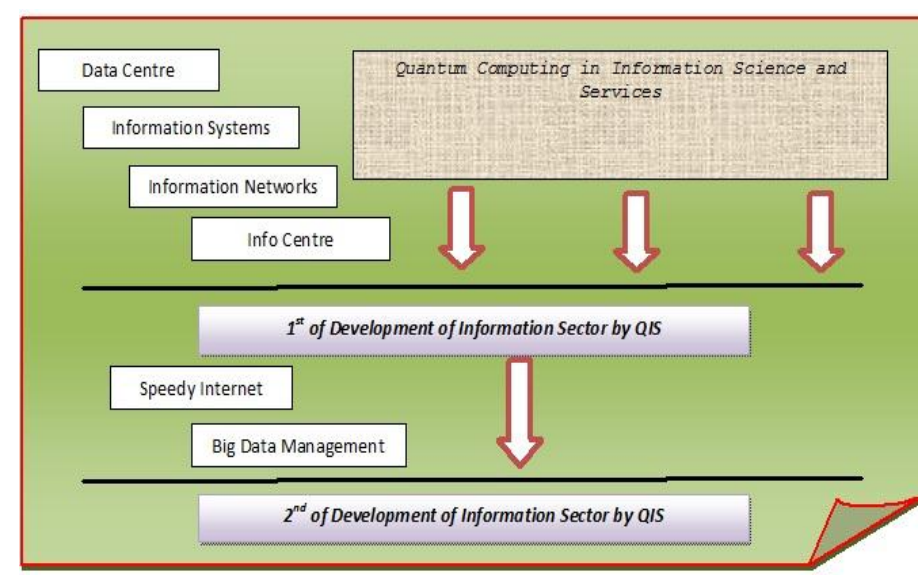

Fig: 5-Depicted QIS and its direct help in Information Networks and overall Information Infrastructure at a glance 
Quantum Information Science also helps in future Information Management; as every year information is getting triple as far size is concerned. Apart from these, in Bog Data Management also, Quantum Information Science has wonderful potentials.

\section{REFERENCE}

[1] Centre of Quantum information science and technology (2013), Home Page, retrieved from http://cqist.usc.edu/ retrieved date-12-09-2013.

[2] Cohen, E. B. (2004). Applying the Informing Science Framework to Higher Education: Knowledge Development, Management, and Dissemination. Konferencja Pozyskiwanie wiedzy i zarządzanie wiedzą (Proceedings of the Knowledge Acquisition and Management Conference) May 13-15, Kule, Poland.

[3] Cohen, Eli B. and Nycz Malgorzata (2006). Learning Objects and ELearning: an Informing Science Perspective. Interdisciplinary Journal of Knowledge and Learning Objects Volume 2, 2006

[4] L Viola et. al. (2001). 'Experimental realization of noiseless subsystems for quantum information processing' Science, retrieved from http://www.sciencemag.org

[5] Martin, S.B. (1998). Information technology, employment, and the information sector: Trends in information employment 1970-1995. Journal of the American Society for Information Science, 49(12), 1053-1069.

[6] Michael Buckland and Ziming liu (1995).History of information science. Annual Review of Information Science and Technology vol. 30: 385-416.

[7] NSF (1999) Workshop QIS: An Emerging Field of Interdisciplinary Research and Education in Science and Engineering, Arlington, Virginia, NSF, US.

[8] Pau1, Prantosh Kumar, R. Senthamarai, A Bhuimali, D. Chatterjee, (2016). Quantum Information Science And Its Requirement For Sophisticated Information Systems Building" in International Journal of Chemical Sciences, 14 (S/1), Page-257-265.

[9] Paul, Prantosh Kumar, D. Chatterjee, A. Bhuimali, M. Ghose, Poovammal. E, R. Rajesh, R. Senthamarai, (2016). Quantum Information Science: Current Scenario and Future Prospects with Possible Academic Potentiality in Indian Educational Context. International Journal of Information Science and Computing: Vol. 3 No. 1, Page-21-30.

[10] Paul, Prantosh Kumar, "Quantum Information Science- Domain of Future Information Management in Organization and Enterprises: Emerging Interdisciplinary Scenario" in SIT Journal of Management, Vol. 3 No. 2, December, 2013, Page 543-551.

[11] Paul, Prantosh Kumar, Mrinal K. Ghose, Minakshi Ghosh and Jhuma Ganguly (2015) MSc Information Science (Quantum Information Science) Specialization: Its Requirement and Proposed Model for Future I-School Dedicated to Next Generation InformationTechnology-Community Interaction in SRELS Journal of Information Management, Vol.52 No.2, April 2015, Page 9-15, DOI: 10.17821/srels/2015/v52i2/61940.

[12] Paul, Prantosh Kumar, Dipak Chaterjee and B B Sarangi, A Kumar, R Chetri (2012). Information Management: Emphasizing its different angel and view with special reference to manpower development programme in India. IJIDT International Journal of Information Dissemination \& Technology,MMU,Ambala. Vol-2 .No-2., AprilJune, 2012, Page-112-117.

[13] Paul, Prantosh Kumar, (2013). Information Systems: From Meaning to its Changing Domain at a Glance" in Abhinav National Journal of Science and Technology, Vol. 2, No. 11, Page-1-08.
[14] Reichman, F. (1961). Notched Cards. In R. Shaw (Ed.), The state of the library art04(01), pp. 11-55). New Brunswick, NJ: Rutgers, The State University, Graduate School of Library Service.

[15] Saracevic, T. (1996). Relevance reconsidered. Information science: Integration in perspectives. In Proceedings of the Second Conference on Conceptions of Library and Information Science (pp. 201-218), Copenhagen, Denmark: Royal School of Library and Information Science.

[16] Saracevic, T. (1975). Relevance: A review of and a framework for the thinking on the notion in information science. Journal of the American Society of Information Science, 26(6), 321-343.

[17] Saracevic, T. (1979a). An essay on the past and future of information science education. I. Historical overview. Information Processing \&Management, 15(1), 1-15.

[18] Saracevic, T. (1979b). An essay on the past and future of information science education. II. Unresolved problems of 'extemalities' of education Information Processing \& Management, 15(4), 291-301.

[19] University College London, UCL Quantum Technologies, retrieved from http://www.ucl.ac.uk/quantum retrieved date-12-09-2013

[20] Vedral, V. (2006) Introduction to Quantum Information Science (Oxford Graduate Texts), retrieved from dl.acm.org

[21] Vakkari, S.P. (1996). Library and information science: Content and scope. In J. Olaisen, E. Munch-Petersen, \& P. Wilson (Eds.), Information science: From development of the discipline to social interaction. Oslo, Norway: Scandinavian University Press.

[22] Vickery, B.C., \& Vickery, A. (1987). Information science in theory and practice. London: Butterworths.

[23] Wersig, G., \& Neveling, U. (1975). The phenomena of interest to information science. Information Scientist, 9, 127-140.

[24] White, H.D., \& McCain, K.W. (1997). Visualization of literatures. Annual Review of Information Science and Technology, 32, 99-168.

[25] http://www.en.wikipedia.org/ Quantum Information Science

[26] http://www.infosci.cornell.edu/

[27] http://www.ischools.org

[28] http://www.libsci.sc.edu/bob/istchron/iscnet/ischron.html 